\title{
The First Patient with COVID-19 in Our Hospital and the Clinical Results of the Approaches at the Beginning of the Pandemic
}

\author{
(D) Hayrunnisa Aksoy Mayda1, (D) Yücel Arman¹, (D) Taner Yıldırmak², (D) Mine Adaş¹ \\ 1 Prof. Dr. Cemil Taşçıoğlu City Hospital, Clinic of Internal Medicine, Istanbul, Turkey \\ 2 Prof. Dr. Cemil Taşçığlu City Hospital, Clinic of Infectious Diseases and Clinical Microbiology, İstanbul, Turkey
}

\section{Abstract}

Severe Acute Respiratory syndrome coronavirus firstly appeared on December 2019 in Wuhan, China then It started to spread whole world and became a global epidemic in a very short time. On March 11, 2020, It is declared as a pandemic by the World Health Organization and within the same day, the first case o the new Coronavirus Disease-2019 (COVID-19) in Turkey was detected and declared by the Turkish government. In this case report, we examined the hospitalization and diagnosis process of our hospital's first COVID-19 case who was being followed up firstly at the internal medicine clinic outside of the pandemic area. Moreover, we aimed to note the results of our first approaches to cases in the early stage of the pandemic and its effects on our all health personnel team.

Keywords: COVID-19, SARS-CoV-2, health personnel

\section{INTRODUCTION}

The new Coronavirus Disease-2019 (COVID-19) is a viral illness that has a clinical course ranging from simple cold to severe acute lung failure. It's agent is Severe Acute Respiratory syndrome coronavirus, which has a newly defined enveloped virus structure. This virus is transmitted from person to person through droplets and contact (1).

Since it is a newly described virus, the dynamics of the virus cannot be fully characterized, so the risk of being infected in the pandemic is high. The control of the pandemic and the steps taken in this regard are handled nationally, institutionally and individually. Healthcare workers are at risk of being infected in such pandemics and are also a risk factor in terms of contagion. With this case report, we examined the hospitalization process of the first patient with COVID-19 in our hospital, who was admitted to our internal medicine clinic and diagnosed in our clinic before the first case was identified in our country. We evaluated the results of our approaches in the early stages of the pandemic in terms of healthcare personnel through this phenomenon.

\section{CASE PRESENTATIONS}

A 81-year-old female patient, who complained of shortness of breath and general deterioration, was admitted to the emergency room on 8 March 2020. She was hospitalized in the internal medicine clinic to investigate the etiology of dyspnea and hypoxia. The patient, who had a history of hypertension and ischemic cerebrovascular disease, was dyspneic and disoriented, and had difficulty in establishing cooperation during the examination. In physical examination; blood pressure was $110 / 80 \mathrm{mmHg}$, pulse $88 / \mathrm{min}$ and rhythmic, fever $36.5^{\circ} \mathrm{C}$, and blood oxygen saturation 82\% (at room air). In respiratory system examination; bilateral respiratory sounds were reduced and no features were detected in other system examinations. In laboratory examinations; white blood cell count was 6.97x103/ uL (3.8-10), lymphocyte count 3x103/uL (1.18-3.74), hemoglobin

Phone: +90 5428253318 E-mail: hayrunnisa.aksoy@hotmail.com ORCID ID: orcid.org/0000-0001-8594-3136

Cite this article as: Aksoy Mayda H, Arman Y, Yıldırmak T, Adaș M. The First Patient with COVID-19 in Our Hospital and the Clinical Results of the Approaches at the Beginning of the Pandemic. Eur Arch Med Res 2020;36(Suppl 1):68-71

๑Copyright 2020 by the University of Health Sciences Turkey, Prof. Dr. Cemil Taşçıoğlu City Hospital

European Archives of Medical Research published by Galenos Publishing House. 
$11.4 \mathrm{~g} / \mathrm{L}$ (115-155), C-reactive protein (CRP) $33.5 \mathrm{mg} / \mathrm{L}(0-5)$, procalcitonin $<0.12 \mu \mathrm{g} / \mathrm{mL}(0-0.12)$, ferritin $320.7 \mu \mathrm{g} / \mathrm{L}(11-$ 306.8), lactate dehydrogenase $206 \mathrm{U} / \mathrm{L}(0-248)$, and in arterial blood gas under oxygen; pH 7.51 (7.37-7.45), $\mathrm{SO}_{2}$ 95.3\% (95-99), partial pressure of oxygen $66.3 \mathrm{mmHg}(70-100)$, partial pressure of carbon dioxide $32.2 \mathrm{mmHg}$ (35-46), and Bicarbonat-actual $25.6 \mathrm{mmol} / \mathrm{L}$ (21-26). Electrocardiogram was in sinus rhythm.

The computed tomography (CT) of the patient who was desaturated without oxygen, did not have an infiltration suggesting infection and/or malignancy. In transthoracic echocardiography; ejection fraction was $60 \%$, pulmonary artery pressure was $30 \mathrm{mmHg}$ and left ventricular hypertrophy, valve degeneration, mild aortic and mitral valve insufficiency were detected. Considering the patient's comorbid diseases and general condition, CT angiography was performed for the etiology of hypoxia to exclude pulmonary embolism. In angiography; upon detection of a filling defect consistent with embolism in the lower lobe posterior segment branch of the right pulmonary artery, enoxaparin 2x6000 IU was initiated subcutaneously. In bilateral lower extremity venous Doppler ultrasound imaging performed for etiology, no finding of thrombus was detected.

On March 11, 2020, the first patient with COVID-19 was detected in our country and a pandemic was also declared. Meanwhile, fever occurred in our patient, who was on the $3^{\text {rd }}$ day of her hospitalization, and there was suspicion in terms of COVID-19. When the history of the patient was deepened, it was learned that on February 26, 2020, family members had contact with their relatives from abroad and some of these people developed symptoms of upper respiratory tract infection. In the examinations requested after emergence of fever; white blood cell count was $4.43 \times 10^{3} / \mathrm{uL}$, lymphocyte count $1.22 \times 10^{3 /}$ $\mathrm{uL}$, CRP $127 \mathrm{mg} / \mathrm{L}$, and procalcitonin $<0.12 \mu \mathrm{g} / \mathrm{mL}$. Significant decrease in lymphocyte values compared to what was measured during hospitalization and no increase in procalcitonin level despite high CRP were common findings in COVID-19. There upon, control thorax CT of the patient was performed. On CT, a diffuse infiltration pattern accompanied by patched ground glass opacities was detected, unlike the CT performed in the emergency room before. Peripheral subpleural ground glass opacities and crazy-paving pattern suggested viral pneumonia (Figure 1, 2). The patient was consulted with the infectious diseases clinic on March 17, 2020. With the pre-diagnosis of COVID-19, a new nasopharyngeal CoV real time polymerase chain reaction (PCR) sample was taken. The patient whose general condition deteriorated was intubated and transferred to the intensive care unit on March 17, 2020 with a pre- diagnosis of COVID-19. The PCR sample taken from the patient twice was negative and the rapid antibody test was positive (Figure 3). The patient, whose clinical, laboratory and imaging findings supported COVID-19, was started on Iopinavir/ ritonavir treatment with hydroxychloroquine. The patient, who developed a cardiac arrest on March 27, 2020, died in the intensive care unit.

Meanwhile, examinations were made in terms of COVID-19, as the family members complied with the possible case definition. Thoracic CT images supported viral pneumonia. These people, whose PCR samples were taken for COVID-19, were taken to home isolation.

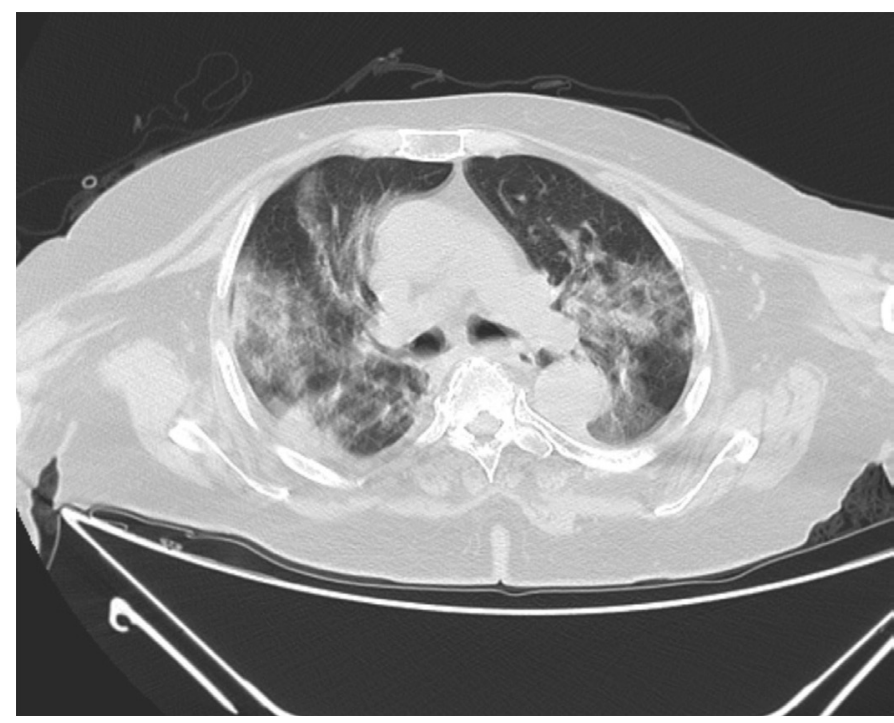

Figure 1. Thorax CT image-1 of our patient $\mathrm{CT}$ : Computed tomography

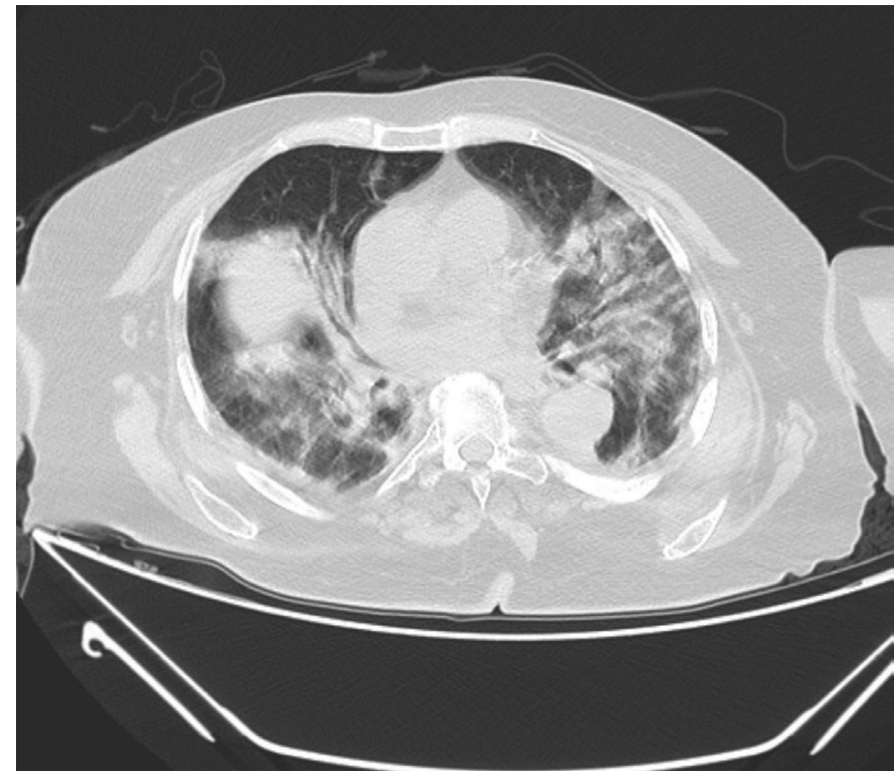

Figure 2. Thorax CT image-2 of our patient CT: Computed tomography 
In line with the precautions taken within the scope of the pandemic in our hospital, the room where 3 more patients were staying together with the patient was isolated. Patient exit from the room and hospitalization in the room were not allowed. Symptom monitoring was initiated in accordance with the algorithms specified in the COVID-19 guide published by the ministry of health for the medical personnel and patients who were in the same room with the patient. The medical staff continued to work by wearing a surgical mask. During the process, symptoms developed in 11 individuals, including physicians and nurses who had multiple exposure with the patient and healthcare professionals in contact with patient

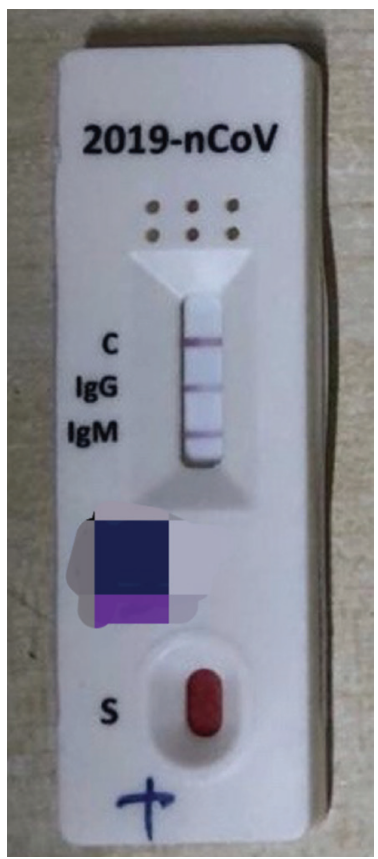

Figure 3. Rapid antibody test result of our patient
(Table 1). The individuals with symptoms were removed from the hospital environment by performing the necessary tests. The health care workers and medical personnel in our clinic with a diagnosis of COVID-19 were among the first ones identified in Turkey.

\section{DISCUSSION}

The novel COVID is transmitted mainly by droplet and contact. It is transmitted by direct contact with the droplets emitted by the sick individuals by breathing, coughing, sneezing, or by bringing hands to the mouth, nose or eye mucosa after hand contact. Asymptomatic people are thought to be infectious, as viruses can be detected in their respiratory tract secretions (2).

At the time of our patient admission to our hospital, there were no defined patients in our country yet, and the number of patients was rapidly increasing all over the world. Considering the possibility of unidentified patients, patients who were admitted to the emergency service and outpatient clinics of our hospital were questioned about symptoms and abroad contact in terms of COVID-19. In our patient, COVID-19 was not considered in the foreground at the time of admission, because the patient's relatives did not give an anamnesis in the direction of abroad contact and there were no findings suggesting viral pneumonia in thoracic CT performed in the emergency service. After the diagnosis of this patient, 11 of our physicians and nurses, who had close contact with the patient, were diagnosed as having COVID-19 in the first 15 days. At the time of submitting our article to the journal, a period of approximately 3 months passed since the beginning of the pandemic in our country. There were 80 physicians and 35 nurses working under our clinic. While 11 personnel were diagnosed as having COVID-19

\begin{tabular}{|c|c|c|c|c|c|}
\hline & Duty & Symptom onset & Symptoms & Thorax CT & $\mathrm{N}-\mathrm{CoV}$ real time $\mathrm{PCR}$ \\
\hline 1 & Resident (1) & 16.03.2020 & Cough, subfebrile fever, headache & Viral pneumonia & Positive \\
\hline 3 & Nurse (1) & 18.02.2020 & Cough, fever, shortness of breath & Viral pneumonia & Negative \\
\hline 4 & Resident (3) & 20.03.2020 & Cough, inability to taste or smell & Normal & Positive \\
\hline 6 & Nurse (2) & 22.03 .2020 & Fever, inability to taste and smell & Viral pneumonia & Negative \\
\hline 7 & Nurse (3) & 24.03 .2020 & Fever, cough, headache & Viral pneumonia & Negative \\
\hline 8 & Resident (4) & 25.03 .2020 & Cough, malaise, myalgia & Viral pneumonia & Negative \\
\hline 9 & Nurse (4) & 26.03 .2020 & Headache, myalgia & Viral pneumonia & Positive \\
\hline
\end{tabular}


in the first 15 days of the pandemic, the number of infected personnel in the next 2.5 months was only 2 .

In our patient, the COVID-19 symptoms emerged simultaneously with the first confirmed patient in our country. The date of the patient's hospitalization coincided with a period when country-wide measures were not strictly implemented yet. With the first patient, personal protection was provided with surgical masks in clinics other than infectious diseases and intensive care units. Especially in the early days, due to both physical conditions and individual adaptation problems, the use of surgical masks and compliance with the distance rule were also hampered by the patients and their attendants. This patient, in whom the history of abroad contact was not given, also increased the risk in terms of transmission.

Considering these conditions, in the first days of the pandemic, the number of healthcare personnel who were initially infected in our clinic due to the lack of knowledge and experience was high. With the serious measures taken afterwards and the increase in our knowledge and experience regarding the disease, a significant decrease was observed in the number of infected healthcare workers. As a result, it is of great importance for the process to carefully comply with all precautionary suggestions of the ministry of health, to raise the awareness of the public and health personnel, and to implement the precautions completely.

\section{Ethics}

Informed Consent: During the follow-up of the patient, consent form could not be obtained due to the death in the intensive care unit.

Peer-review: Externally peer-reviewed.

\section{Authorship Contributions}

Concept: H.A.M., Y.A., M.A., Design: H.A.M., Y.A., T.Y., M.A., Data Collection or Processing: H.A.M., Y.A., T.Y., M.A., Analysis or Interpretation: H.A.M., Y.A., M.A., Literature Search: H.A.M., Y.A., M.A., Writing: H.A.M., Y.A., M.A.

Conflict of Interest: No conflict of interest was declared by the authors.

Financial Disclosure: The authors declared that this study received no financial support.

\section{REFERENCES}

1. World Health Organization. Infection prevention and control during health care when novel coronavirus (nCoV) infection is suspected, 2020. Available from: URL: https://www.who.int/publications-detail/infectionprevention-and-control-during-health-care-when-novel-coronavirus(ncov)-infection-is-suspected-20200125

2. Sağıı Bakanlığı COVID-19 (SARS-CoV-2 ENFEKSIYONU) REHBERI (14 Nisan 2020). Available from: URL: https://www.tjod.org/wp-content/ uploads/2020/04/COVID-19_Rehberi-14.04.2020.pdf 